\begin{abstract}
Juvenile smalltooth sawfish (Pristis pectinata) were monitored in the Peace River, Florida. A series of 37 acoustic receivers was used throughout the river, 9 of which were time synchronized. In 2016, 20 individuals were tagged and tracked from 27 May through 26 October. Most juveniles resided along the northern shoreline during the day, and some individuals crossed the river at night. Eleven smalltooth sawfish were detected on the southern shoreline, and 6 individuals used it extensively. Estimates of the sawfish positions were sorted into 3 habitat types: shallow, deep, and oyster reef. While at the southern shoreline, all sawfish tended to occupy shallow water, and most of them visited the oyster reefs. These results 1) improve our understanding of how the most productive nursery habitats function within the overall nursery, 2) will continue to influence decisions regarding management in this unique nursery, and 3) have implications for recovery planning for other nurseries of this endangered species.
\end{abstract}

\title{
Automated monitoring of fine-scale movements of the endangered smalltooth sawfish (Pristis pectinata)
}

\author{
Rebecca K. May ${ }^{1}$ \\ S. Gregory Tolley ${ }^{1}$ \\ Rachel M. Scharer ${ }^{2}$ \\ Bass Dye ${ }^{1}$ \\ Felix Jose ${ }^{1}$ \\ Gregg R. Poulakis (contact author) ${ }^{1,2}$ \\ Email address for contact author: gregg.poulakis@MyFWC.com \\ ${ }^{1}$ Department of Marine and Ecological Sciences \\ Florida Gulf Coast University \\ 10501 FGCU Boulevard South \\ Fort Myers, Florida 33965 \\ ${ }^{2}$ Charlotte Harbor Field Laboratory \\ Fish and Wildlife Research Institute \\ Florida Fish and Wildlife Conservation Commission \\ 585 Prineville Street \\ Port Charlotte, Florida 33954
}

The term hotspot has been used in many contexts and on a variety of spatial scales to refer to important regions of terrestrial and aquatic ecosystems. Hotspots have been used to describe areas of high plant and animal biodiversity on a global scale (Myers, 1988; Mittermeier et al., 2011), aggregation areas of non-native and native vertebrates, including elasmobranchs, on regional scales (Semmens et al., 2004; Southall et al., 2005; Polovina et al., 2006; Huveneers et al., 2018), and areas of emerging diseases on local scales (Waruhiu et al., 2017). Recently, the term has been used to refer to the most productive nursery habitats for marine fauna (Nagelkerken et al., 2015). Regardless of terminology, a key aspect of this work acknowledges that some portions of nurseries of wellstudied species are used more than others; therefore, results from models that use a single habitat or single life stage can be misleading. For example, Heupel et al. $(2007,2018)$ attempted to define elasmobranch nurseries, and, although their criteria may have improved previous definitions, their model is not adaptable because it applies only to young of the year (YOY) and fails to provide a mechanism for recognizing the most productive habitats within the broader nursery, if they exist. In general, there is much to learn about how marine species use nurseries; therefore, models that attempt to explain this and other complex concepts must be adaptable to acknowledge the myriad ways in which nature sometimes solves the same problems.

In versatility and elegance, Nature's creative effort provides a never-ending source of astonishment and delight. She is tireless and imaginative in her innovations. Having evolved a happy solution to a given problem, it might be expected that she would rest content, adopting her discovery universally. Instead, she seems determined to demonstrate that the same problem can be solved, and solved brilliantly, in many ways and always with a great show of virtuosity (Greenewalt, 1960). 
Most of the occupied nurseries of the smalltooth sawfish (Pristis pectinata), listed as endangered under the U.S. Endangered Species Act (Federal Register, 2003), are in southwest Florida. Charlotte Harbor, located on the Gulf of Mexico, has been identified as 1 of 2 units that compose the critical habitat for promoting recovery of juveniles (Norton et al., 2012). The Charlotte Harbor estuarine system contains 2 distinct nurseries: 1 nursery associated with the Peace River ( $\sim 10 \mathrm{~km}$ long) in the northern portion of the system, and 1 nursery in the Caloosahatchee River in the southern portion ( $25 \mathrm{~km}$ long) (Scharer et al., 2017). In the Caloosahatchee River nursery, there are multiple hotspots, whereas in the Peace River there is only one (Poulakis et al., 2011). These nursery hotspots are important because adult females give birth nearby biennially and the young stay for 1-2 years; as a result, these areas contain multiple year classes and are prioritized for conservation, especially when the entire nursery cannot be preserved (Poulakis et al., 2016; Feldheim et al., 2017). Because criteria to establish broad nurseries and hotspots within nurseries are complementary (Poulakis and Grubbs, 2019), data from nursery hotspots have already influenced key decisions regarding management in southwest Florida $\left(\mathrm{NMFS}^{1}\right)$.

The single hotspot in the Peace River was identified by using public encounter, scientific catch, and acoustic data and was initially thought to be confined to the northern shoreline (Poulakis et al., 2011). However, the boundaries of this hotspot were expanded after active tracking revealed nightly excursions toward the southern shoreline of the river (Huston et al., 2017). Interestingly, smalltooth sawfish have remained associated with this nursery hotspot regardless of seasonal changes in abiotic conditions (Scharer et al., 2017).

In August 2015, the Nature Conservancy began a pilot oyster restoration project along the southern shoreline of the Peace River, given the importance of oysters to overall estuarine health (Beck et al., 2011). Oysters contribute to the health of estuaries by providing water filtration, 3-dimensional habitats, and storm buffering (Coen et al., 2007; Rodriguez et al., 2014). Because the restoration area was within designated critical habitat of juvenile smalltooth sawfish, it became important to determine how juveniles were using this area and to document any interactions they had with the developing reefs.

To document habitat use by smalltooth sawfish in and around the southern shoreline of the Peace River, timesynchronized acoustic receivers were added to a preexisting receiver array to obtain estimates of the position of sawfish accurate to within $5 \mathrm{~m}$. The specific goals of this study were 1) to determine if juveniles were regularly using the southern shoreline of the river, 2) to determine if the timing of river crossing to the southern shoreline was related to the tidal cycle, and 3) to identify any patterns of habitat use and movement along the southern shoreline

\footnotetext{
${ }^{1}$ NMFS. 2019. Unpubl. data. Southeast Reg. Off., Natl. Mar. Fish. Serv., NOAA. 263 13th Ave. S., St. Petersburg, FL 33701.
}

by different age classes (YOY and $\geq$ age 1 ). These data will improve our understanding of how hotspots function as the most productive habitats within smalltooth sawfish nurseries.

\section{Materials and methods}

\section{Study area}

Charlotte Harbor is one of the largest estuaries in Florida with an area of about $700 \mathrm{~km}^{2}$ (Hammett, 1990). The main study area was along the southern shoreline of the Peace River, where an oyster restoration site was located (Fig. 1). Prior to this study, 3 oyster reefs were constructed by the Nature Conservancy $16 \mathrm{~m}$ from shore. The shoreline was dominated by red mangroves (Rhizophora mangle), and the water depth ranged from $0.1 \mathrm{~m}$ along the central and easternmost portions of the main study area to $1.2 \mathrm{~m}$ along the westernmost portion. The tidal regime is mixed semidiurnal, generally resulting in 2 high and 2 low tides of variable heights each day (Zheng and Weisberg, 2004).

\section{Field sampling}

Gill-net sampling for smalltooth sawfish was conducted from February through September 2016 as part of an ongoing research program (Poulakis et al., 2011). Each month, 2 random sampling trips (4 sites per trip) and an average of 2 directed sampling trips (3 sites per trip) were made in upper Charlotte Harbor, including in the Peace River (for details, see Scharer et al., 2017). Directed sampling sites were selected on the basis of historic capture locations or recent encounters reported by the public. All nets were soaked for $1 \mathrm{~h}$ and checked after $0.5 \mathrm{~h}$ or when animals were observed in the net, whichever came first. Sawfish were measured to the nearest millimeter in stretch total length (STL) and tagged prior to release.

\section{Acoustic transmitters}

All captured smalltooth sawfish were externally tagged with 69-kHz Vemco ${ }^{2}$ (Bedford, Canada) V9 acoustic transmitters (hereafter referred to as tags; tag family: V9-2H; code space ID: A69-1303; length: $29 \mathrm{~mm}$; weight in water: $2.9 \mathrm{~g})$. Tags were programmed to emit a unique acoustic sequence every 80-160 s. Delays were used to reduce signal collisions when multiple individuals were within range of the same acoustic receivers and to maximize battery life ( 12 months). The $69-\mathrm{kHz}$ tags also functioned with the existing acoustic receivers deployed broadly throughout the estuary (see the "Acoustic monitoring" section).

\footnotetext{
${ }^{2}$ Mention of trade names or commercial companies is for identification purposes only and does not imply endorsement by the Florida Fish and Wildlife Conservation Commission or the National Marine Fisheries Service, NOAA.
} 


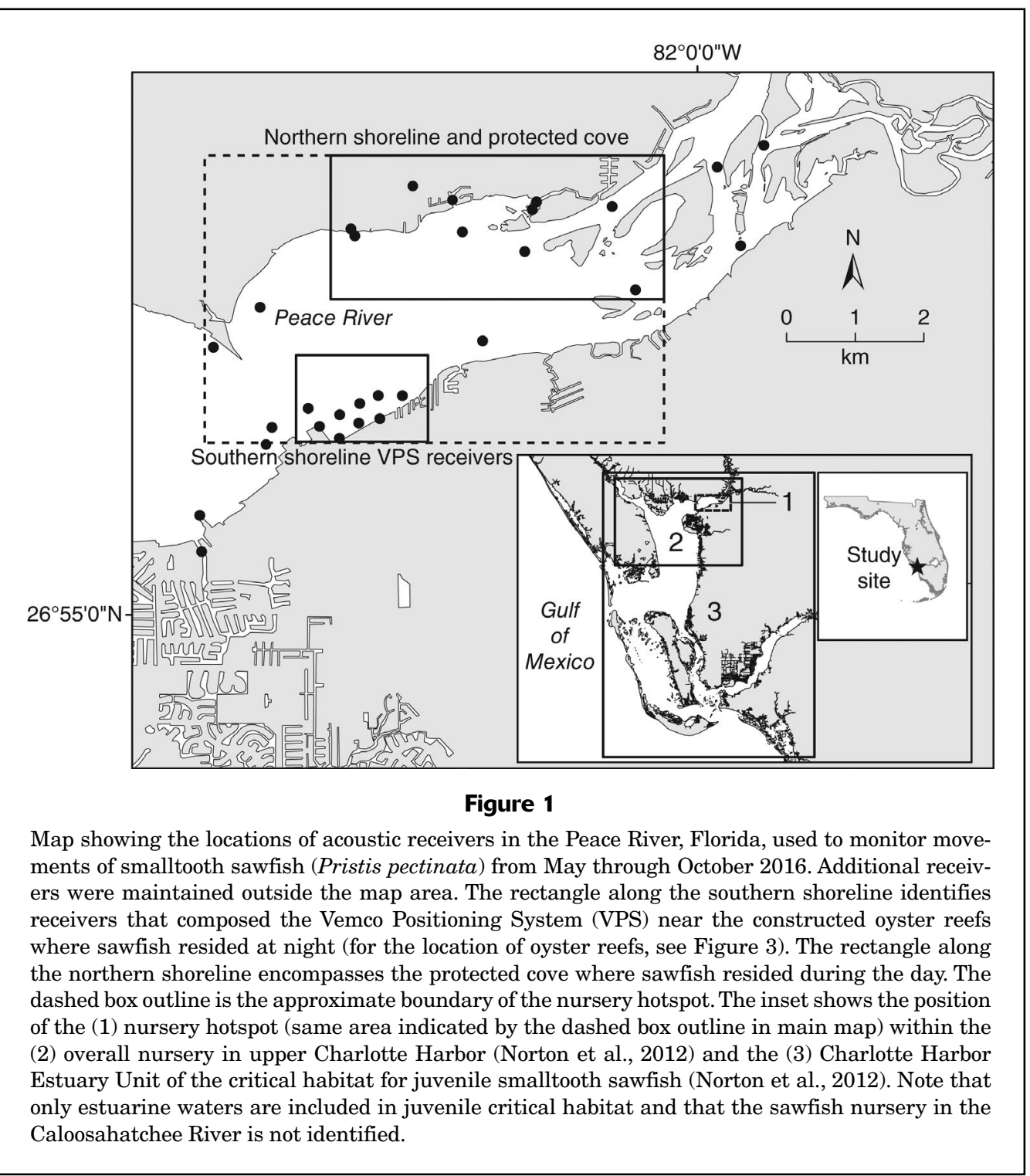

Acoustic tags were prepared in the laboratory for external attachment prior to field sampling by using a cable tie covered with an epoxy gel to attach the acoustic tag to the flat half of a plastic dorsal fin tag (Rototag Identification Tag, $35 \mathrm{~mm}$ long by $9 \mathrm{~mm}$ wide, Dalton ID Systems Ltd., Henley-on-Thames, UK). Tags were applied to the thicker anterior margin of the second dorsal fin: a leather punch was used to make a hole for the projecting half of the Rototag, and then the 2 halves were attached (e.g., Whitty et al., 2009; Poulakis et al., 2013).

\section{Acoustic monitoring}

A total of 37 moored, single-frequency, omnidirectional VR2W or VR2Tx acoustic receivers (Vemco) were maintained in northern Charlotte Harbor, including in the Peace River, to monitor tagged smalltooth sawfish (Fig. 1; Huston et al., 2017; Scharer et al., 2017). When the signal of a tagged sawfish was detected by a receiver (maximum and mean detection ranges: $800 \mathrm{~m}$ and $450 \mathrm{~m}$, respectively; Collins et al., 2008), date, time, and tag number were recorded. Data were downloaded from all receivers, and accumulated biofouling was removed every other month.

\section{Positioning system}

To accurately estimate positions of tagged smalltooth sawfish (hereafter referred to as position estimates) along the southern shoreline of the Peace River, with respect to the constructed oyster reefs, 3 VR2Tx acoustic receivers, 6 VR2W receivers, and 2 spatial reference tags were used to form a Vemco Positioning System (VPS; Fig. 1). These receivers were time synchronized to estimate positions of tagged sawfish on the basis of the times signals were received at each receiver (Özgül et al., 2015). The 6 VR2W 
receivers required time-synchronization tags, which were placed $1 \mathrm{~m}$ from each receiver. VR2Tx receivers did not require external time-synchronization tags. Moored spatial reference tags were used to improve accuracy of position estimates. Functionality of the VPS was tested by using a V9 tag attached to the bottom of a pole to mimic the location of a sawfish.

\section{Tide modeling}

To investigate the influence of tidal fluctuations on habitat use by smalltooth sawfish near the shallow oyster reefs, a 2-dimensional hydrodynamic model (MIKE 21/3 Flow Model-FM, DHI Water and Environment, Hørsholm, Denmark) was calibrated to the study area (Dye et al., in press). This model simulated water transport when forced by variations in wind, temperature, salinity, freshwater discharges, and tides (Allahdadi et al., 2017). For the initial model, bathymetric data were obtained from the South Florida Water Management District (100-ft digital elevation model for the Lower West Coast region, available from website) and the General Bathymetric Chart of the Oceans (GEBCO_2014 Grid, available from website). To calibrate the model to the study site, water depth measurements were taken along 5 transects perpendicular to shore ( 6 or 7 measurements per transect), and latitude, longitude, and time of day were recorded to relate water depth to the tidal cycle. Tide data from the Tides and Currents website of NOAA's National Ocean Service for 2 stations, Locust Point (available from website) and Port Boca Grande (available from website), were also used to validate the modeled tidal heights. The model was run for the entire study period (27 May-26 October 2016) to discern when and where the receivers may have been too shallow to function effectively or were exposed at low tide.

For analyses, tidal phase was separated into two 6-h categories: ebbing and flooding. Position estimates for smalltooth sawfish were analyzed by using these 2 categories and were standardized as counts of detections per hour during each period (O'Shea et al., 2010). One test compared flooding to ebbing. Two other tests were conducted in recognition of the mixed semidiurnal tides of the study area: first and second occurrences were compared for both flooding and ebbing. Slack water was not investigated because the model outputs were hourly. These analyses were conducted by using Statgraphics Centurion 18 (Statpoint Technologies Inc., The Plains, VA). Because variances were unequal and the normality assumption was violated, non-parametric Kruskal-Wallis tests were used to test for differences in number of position estimates by tidal stage.

\section{Analyses of movement and habitat use}

Acoustic data were collected from 27 May through 26 October 2016 within the VPS. Raw detection data were sent to Vemco for determination of position estimates for individual smalltooth sawfish. Before further analysis, position estimates were filtered on the basis of their horizontal positioning errors (HPEs) following Scheel and Bisson (2012); only position estimates with HPE values $<20$ were analyzed because these estimates were likely within $5 \mathrm{~m}$ of the actual location.

Next, to determine habitat use within the VPS, polygons corresponding to 3 habitat types were created and defined as shallow ( $\leq 1 \mathrm{~m}$ ), deep ( $>1 \mathrm{~m}$ ), and oyster reef (all oyster restoration areas combined) for grouping position estimates. One meter was used to separate shallow and deep habitats because shallow depths are important for small juveniles (Norton et al., 2012). A likelihood ratio chisquare test (Cressie and Read, 1989; Rogers and White, 2007) was used to compare position estimates between shallow, deep, and oyster polygons (by using JMP 14, SAS Institute Inc., Cary, NC). This test was based on the area of the polygons (shallow: $0.12 \mathrm{~km}^{2}$; deep: $1.74 \mathrm{~km}^{2}$; and oyster: $0.002 \mathrm{~km}^{2}$ ), with a significance level of 0.05 , and compared the ratios of actual use of these habitats to what would be expected on the basis of random chance. Tests were run for all position estimates combined and then for position estimates for each individual sawfish separately because pooling position estimates would have eliminated the ability to identify individual variation. Bonferroniadjusted confidence intervals (CIs) were also calculated to explore variation around the selection ratios and provide a conservative measure of reliability (Neu et al., 1974; Rogers and White, 2007). In general, ratios $>1$ indicate selection for a habitat type, and ratios $<1$ indicate selection against a habitat type.

By using river-wide data, contour maps were created with the software Surfer 13 (Golden Software LLC, Golden, CO) to visualize large-scale patterns of habitat use and movement, with regard to the nursery hotspot boundary (see inset in Figure 1). Raw data were reduced by selecting the first detection per hour per receiver for each individual, by using SAS 9.4 (SAS Institute Inc.), to eliminate the chance of data for 1 or 2 individuals biasing the results (Huston et al., 2017). These maps were used to visualize presence of smalltooth sawfish throughout the river by time period (day: 0900-1659; night: 2100-0559; crepuscular periods were omitted following Poulakis et al., 2013) and by age class following Scharer et al. (2012). Age classes were based on length (YOY:

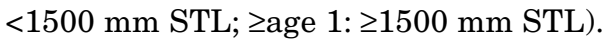

\section{Results}

In 2016, 20 smalltooth sawfish (726-1770 mm STL) were caught and tagged in upper Charlotte Harbor during daytime sampling (Peace River: number of tagged fish $[n]=19$; Myakka River: $n=1$; Table 1). Most individuals were caught along the northern shoreline of the Peace River within the nursery hotspot, and none were captured along the southern shoreline portion of the hotspot near the VPS. Both age classes, YOY $(n=16)$ and $\geq$ age 1 $(n=4)$, were represented. Of the 20 tagged individuals, 11 sawfish (55\%) were detected within the VPS on the 


\section{Table 1}

Details for smalltooth sawfish (Pristis pectinata) caught and tagged with acoustic transmitters in upper Charlotte Harbor, Florida, including in the Peace River, in 2016, by tagging date (month/day/year). All individuals received uniquely coded $69-\mathrm{kHz}$ acoustic tags. An asterisk indicates an individual that was detected within the array of acoustic receivers in the Vemco Positioning System (VPS) along the southern shoreline or that spent enough time in the area of the VPS to be analyzed in detail. STL=stretch total length.

\begin{tabular}{ccrrrrr}
\hline $\begin{array}{l}\text { Sawfish ID } \\
\text { number }\end{array}$ & Sex & $\begin{array}{c}\text { Date } \\
\text { tagged }\end{array}$ & $\begin{array}{c}\text { Date of last } \\
\text { detection }\end{array}$ & $\begin{array}{c}\text { STL } \\
(\mathrm{mm})\end{array}$ & $\begin{array}{c}\text { Detected } \\
\text { by VPS }\end{array}$ & $\begin{array}{c}\text { Used VPS } \\
\text { area }\end{array}$ \\
\hline 1 & $\mathrm{M}$ & $3 / 8 / 2016$ & $1 / 4 / 2017$ & 1432 & $*$ & \\
2 & $\mathrm{~F}$ & $3 / 8 / 2016$ & $7 / 31 / 2016$ & 1321 & $*$ & $*$ \\
3 & $\mathrm{M}$ & $3 / 15 / 2016$ & $8 / 20 / 2016$ & 1435 & $*$ & \\
4 & $\mathrm{~F}$ & $4 / 22 / 2016$ & $4 / 14 / 2017$ & 726 & $*$ & \\
5 & $\mathrm{~F}$ & $4 / 26 / 2016$ & $6 / 11 / 2016$ & 952 & & \\
6 & $\mathrm{M}$ & $4 / 26 / 2016$ & $10 / 28 / 2016$ & 988 & & \\
7 & $\mathrm{M}$ & $4 / 26 / 2016$ & $5 / 16 / 2016$ & 957 & & \\
8 & $\mathrm{M}$ & $4 / 26 / 2016$ & $2 / 18 / 2017$ & 1028 & & \\
9 & $\mathrm{M}$ & $4 / 26 / 2016$ & $7 / 7 / 2016$ & 1001 & & \\
10 & $\mathrm{M}$ & $4 / 26 / 2016$ & $6 / 20 / 2016$ & 943 & & \\
11 & $\mathrm{~F}$ & $5 / 9 / 2016$ & $6 / 28 / 2016$ & 889 & & \\
12 & $\mathrm{~F}$ & $5 / 9 / 2016$ & $8 / 5 / 2016$ & 1010 & & \\
13 & $\mathrm{~F}$ & $5 / 9 / 2016$ & $4 / 26 / 2017$ & 891 & $*$ & $*$ \\
14 & $\mathrm{~F}$ & $5 / 9 / 2016$ & $6 / 27 / 2016$ & 903 & $*$ & $*$ \\
15 & $\mathrm{M}$ & $5 / 9 / 2016$ & $5 / 30 / 2017$ & 1160 & $*$ & \\
16 & $\mathrm{~F}$ & $5 / 18 / 2016$ & $8 / 23 / 2016$ & 1032 & $*$ & $*$ \\
17 & $\mathrm{M}$ & $5 / 18 / 2016$ & $3 / 2 / 2017$ & 915 & $*$ & $*$ \\
18 & $\mathrm{~F}$ & $6 / 3 / 2016$ & $12 / 5 / 2016$ & 1019 & $*$ & \\
19 & $\mathrm{~F}$ & $6 / 28 / 2016$ & $12 / 29 / 2016$ & 897 & $*$ & \\
20 & $\mathrm{~F}$ & $7 / 5 / 2016$ & $8 / 15 / 2016$ & 1770 & & \\
& & & & & & \\
\end{tabular}

southern shoreline (mostly at night), and 6 sawfish spent enough time there to be analyzed in detail. Throughout the 153-d study period (27 May-26 October), there were $115 \mathrm{~d}(75 \%)$ during which the VPS detected at least 1 sawfish. During 85 d (56\%), multiple sawfish were detected.

\section{Positioning system}

The tide model validated water depths recorded in the field. Most modeled water depths were within $0.5 \mathrm{~m}$ of the measured depths, and results from the model indicate that the shallowest receiver remained submerged during the entire study (receiver depth: $0.1 \mathrm{~m}$; lowest water depths were $0.2 \mathrm{~m}$ on $4 \mathrm{~d}$ in October). Therefore, water level should not have affected overall functioning of the array of acoustic receivers in the VPS.

Once the tide model was validated, the relationship between the presence of juveniles and tide stage was quantified (Fig. 2). Detections of tagged smalltooth sawfish occurred during 95 of the 295 flood tide stages (32\%) and 99 of the 296 ebb stages (34\%). There was no significant difference in median detections per hour along the southern shoreline between flood and ebb tides (Kruskal-Wallis test: $H=0.7417, P=0.4)$. However, there was a significant difference in median detections per hour between the first and second tide occurrences for both flood (Kruskal-Wallis test: $H=63.23, P<0.0001)$ and ebb (Kruskal-Wallis test: $H=12.88, P=0.0003)$ periods. The majority of the first flood and first ebb tides occurred at night $(75 \%$ and $74 \%$, respectively, excluding crepuscular occurrences).

Habitat polygons created for the major habitat types found within the study area provided insight into how juveniles used shallow, deep, and oyster habitats, with a significant difference in the ratio of observed to expected frequencies detected among pooled position estimates (likelihood ratio chi-square test: $G^{2}=3465, P<0.0001$, $\mathrm{df}=2$; Table 2).

To explore differences indicated by results from the likelihood ratio chi-square tests (Table 2), selection ratios were calculated. All but 1 juvenile selected the shallow or oyster habitats. This pattern was consistent when analyzing position data for all 6 sawfish combined, with a selection ratio of 3.770 (95\% CI: 2.223-5.317) for shallow habitats, 0.828 (95\% CI: 0.726-0.930) for deep habitats, and 3.570 (95\% CI: 1.058-6.082) for oyster habitats. These data indicate that smalltooth sawfish were selecting against the deep habitat type and for shallow and 


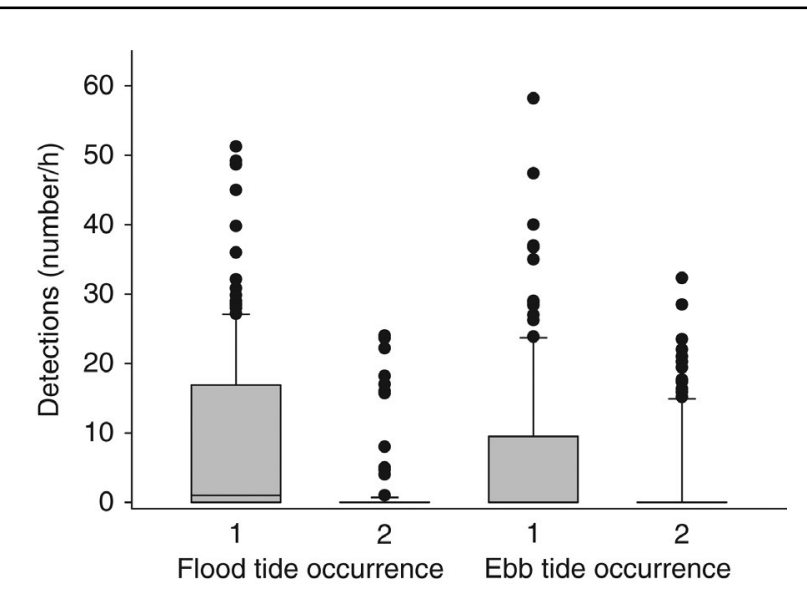

Figure 2

Activity of tagged smalltooth sawfish (Pristis pectinata) relative to the mixed semidiurnal tidal regime of the study area in the Peace River, Florida, from May through October 2016. Box plots from Kruskal-Wallis tests compare the median number of detections per hour of 6 sawfish within an array of acoustic receivers between the first and second flood tides each day and between the first and second ebb tides each day. The bottom and top boundaries of the box represent the 25 th and 75 th percentiles, respectively, of the number of detections per hour. The line within the box is the median value. Whiskers above the boxes indicate the 90 th percentiles. Black circles indicate outlying values for upper ranges. Significantly more position estimates were placed on the southern shoreline during the first flood and first ebb tides (regardless of height), which typically occurred at night. Because these first tides typically occurred at night, the primary driver for the across-river movement was likely diel, rather than tidal.

oyster habitats. The wide CI for oyster habitats reflects greater variability in associations of sawfish with this habitat.

Although there were differences in habitat use among individuals, both size classes used all available habitats, and 5 of 6 individuals crossed over the oyster habitats (Table 2; Fig. 3). Furthermore, because most juveniles crossed the constructed oyster reefs, they were not actively avoiding the developing reefs.

Use of the southern shoreline varied ontogenetically, with detections of age-1 or older individuals peaking in June. Although a small number of detections of YOY occurred in June and July, detections in the VPS of YOY peaked in August and September.

\section{Hotspot-wide movement patterns}

In general, smalltooth sawfish made diel movements in the Peace River (Fig. 4). During the day, sawfish were concentrated near the protected cove portion of the northern shoreline as well as farther downriver along the northern shoreline. At night, they were still concentrated in these 2 areas but were more numerous downriver.

\section{Table 2}

Comparison of results from likelihood ratio chi-square tests $\left(G^{2}\right)$ and selection ratio tests $\left(\hat{w}_{\mathrm{ij}}\right)$ for the 6 smalltooth sawfish (Pristis pectinata) detected frequently from May through October 2016 near the constructed oyster reefs along the southern shoreline of the Peace River, Florida. Sawfish were tagged with acoustic transmitters and tracked with an array of acoustic receivers in 3 habitat types: shallow ( $\leq 1 \mathrm{~m})$, deep $(>1 \mathrm{~m})$, and oyster reef. Selection ratios $>1$ indicate selection for a habitat type; ratios $<1$ indicate selection against a habitat type. Sawfish ID numbers correspond to those in Table 1. For habitat descriptions, see the "Materials and methods" section.

\begin{tabular}{crrrrrrr}
\hline & & & & \multicolumn{4}{c}{$\hat{w}_{\mathrm{ij}}$} \\
\cline { 5 - 7 } $\begin{array}{l}\text { Sawfish ID } \\
\text { number }\end{array}$ & \multicolumn{1}{c}{$G^{2}$} & $\mathrm{df}$ & $P$ & Shallow & Deep & Oyster \\
\hline 3 & 1983.25 & 2 & $<0.01$ & 4.84 & 0.76 & 5.56 \\
15 & 1030.70 & 2 & $<0.01$ & 4.03 & 0.81 & 3.39 \\
16 & 30.50 & 2 & $<0.01$ & 1.82 & 0.89 & 2.32 \\
17 & 38.50 & 2 & $<0.01$ & 1.53 & 0.98 & 0.00 \\
18 & 447.83 & 2 & $<0.01$ & 7.75 & 0.57 & 5.81 \\
19 & 507.82 & 2 & $<0.01$ & 4.22 & 0.80 & 4.62 \\
& & & & & & \\
\hline
\end{tabular}

Although some individuals moved only along the northern shoreline, smalltooth sawfish used both shorelines (Fig. 5). The majority (91\%) of detections at the VPS occurred at night, and over half $(63 \%)$ of the daytime detections were of the largest individual. Sample size was low, but this finding suggests that there are ontogenetic differences in hotspot-wide habitat use: larger juveniles (>1500 mm STL) were more likely to make farther excursions during the day.

Diel movements were evident within the entire nursery hotspot over short time scales (e.g., 1 week; Fig. 6) and over the course of the entire study (Fig. 7). Individuals generally remained along the northern shoreline during the day and made nightly excursions toward the middle of the river, sometimes to the southern shoreline, and back.

\section{Discussion}

Currently, for the smalltooth sawfish in the United States, habitat use by juveniles is monitored and related management actions can be implemented on 3 spatial scales (see inset in Fig. 1). First, nursery hotspots are relatively discrete areas within the broader nursery where YOY and juveniles age 1 or older commonly occur over many years (i.e., the most productive nursery habitats; Nagelkerken et al., 2015). Young may be born elsewhere in the broader nursery, but they tend to go to nursery hotspots and spend most of their time there, even when disturbances, such as tropical storms or cold fronts, temporarily disrupt normal patterns of habitat use (Poulakis et al., 2016; Scharer et al., 2017). Therefore, nursery hotspots often contain at least 2 year classes and become 


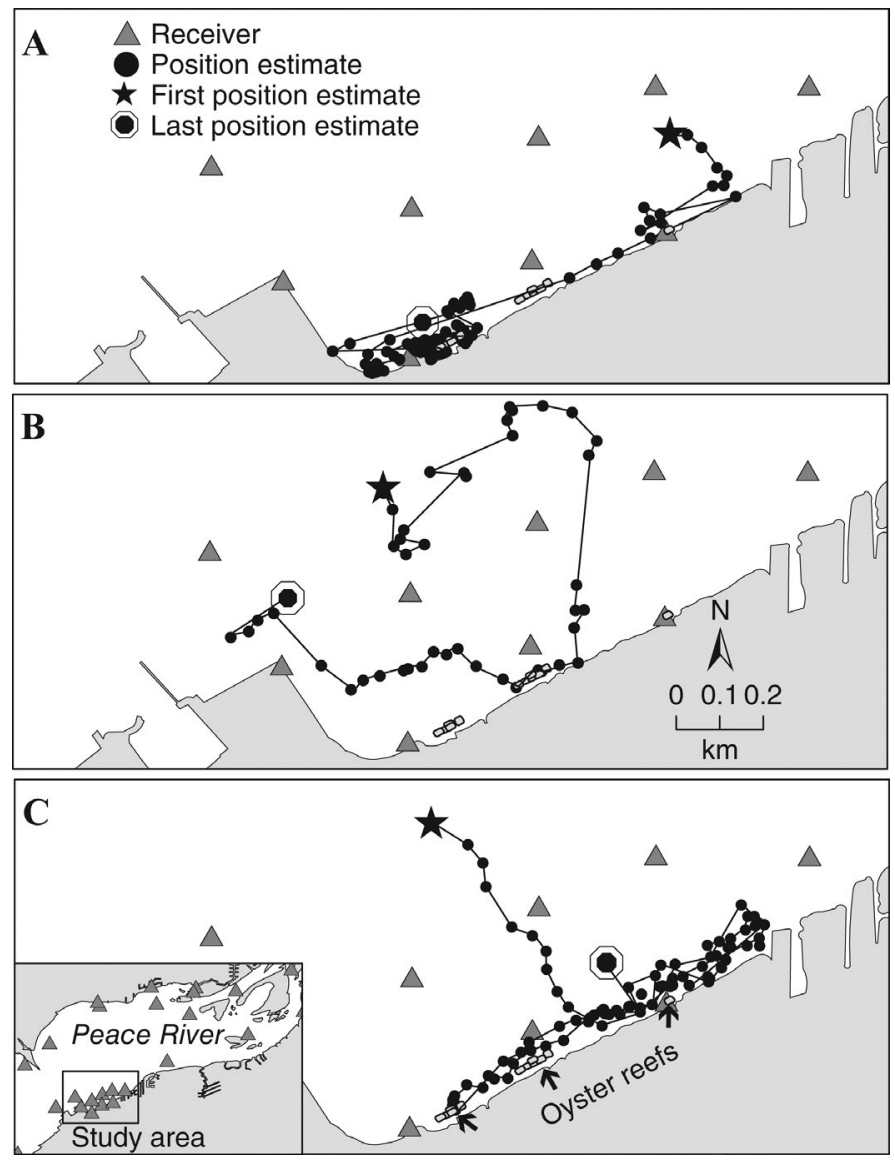

Figure 3

Maps showing the receiver locations and position estimates for 3 tagged young-of-the-year smalltooth sawfish (Pristis pectinata) when they interacted with the constructed oyster reefs in 2016 in the Peace River, Florida. Receivers shown were time synchronized to estimate positions of tagged sawfish based on the time that signals were received at each receiver. Each map presents position estimates during a short time segment for each sawfish: (A) sawfish 18, detected on 7 June from 0423 to 1359; (B) sawfish 16, detected on 5 July from 0100 to 0803 ; and (C) sawfish 19, detected on 9 October from 0043 to 0622 (sawfish ID numbers correspond to those in Table 1). The inset in the lower left corner shows the entire study area.

variations of these spatial scales and the life history stages within them; therefore, adapting these ideas as results from future studies emerge would be expected.

Within the Charlotte Harbor Estuary Unit of critical habitat for smalltooth sawfish, there are 2 distinct nurseries in the Peace and Caloosahatchee Rivers (Norton et al., 2012; Feldheim et al., 2017). Within those sawfish nurseries, 5 hotspots have been identified (Poulakis et al., 2011, 2016). The Peace River has only one known hotspot, and its approximate boundaries, within the broader nursery, have been refined through recent research (Huston et al., 2017). In our study, using relatively new technology, we further refined habitat use within the hotspot and identified sawfish behavior associated with the southern shoreline of the Peace River. Collectively, the results of these studies have already resulted in management decisions $\left(\mathrm{NMFS}^{1}\right.$ ) and have served to enhance our understanding of the early life history of this endangered species. This research has never been used to restrict previous nursery designations, as was recently suggested by Heupel et al. (2018). In fact, the concepts of nursery and nursery hotspot are complementary and help prioritize areas for management and conservation actions (Poulakis and Grubbs, 2019). Both of these concepts should be considered as more research is conducted on this and other elasmobranch species, especially if they occur in regions where substantial habitat loss could occur and data to support management and conservation actions may be required to sustain or recover populations.

As in previous studies (Poulakis et al., 2016; Huston et al., 2017; Lear et al., 2019), diel behaviors were observed in this study. In general, smalltooth sawfish resided along the northern shoreline of the Peace River in a protected cove during the day and ventured away from the cove and toward the southern shoreline at night. However, because of the increased accuracy of the time-synchronized array of acoustic receivers, which provided continuous tracking data for this study, complete crossing of the river was

conservation priorities when preserving the entire nursery is not possible. Second, the nursery itself encompasses any hotspots, and the corridors between them, where young may remain for their first 2-3 years (Norton et al., 2012). Third, for this species, juvenile critical habitat is purely a management designation required in the United States as part of the Endangered Species Act and encompasses all nurseries and the non-nursery habitats that connect them. There are 2 large units of juvenile critical habitat for this species, 1 unit encompasses the Charlotte Harbor estuarine system, where this study was conducted, and the other includes the entire Ten Thousand Islands region and Everglades National Park (Norton et al., 2012). Other elasmobranchs are likely to have documented for the first time with near-exact, autonomously recorded GPS locations of the sawfish. Both size classes remained along the northern shoreline during the day, but individuals age 1 or older began to use the entire hotspot, including the southern shoreline, well before YOY, a difference that may relate to known ontogenetic changes in the areas where individuals are active and in the depths where they occur throughout the range of this species (Simpfendorfer et al., 2010; Poulakis et al., 2011, 2013; Brame et al., 2019).

Restoration projects have become necessary to promote recovery of oyster populations and to enhance accretion rates (Coen et al., 2007; Rodriguez et al., 2014). Juvenile smalltooth sawfish are known to frequent shallow 


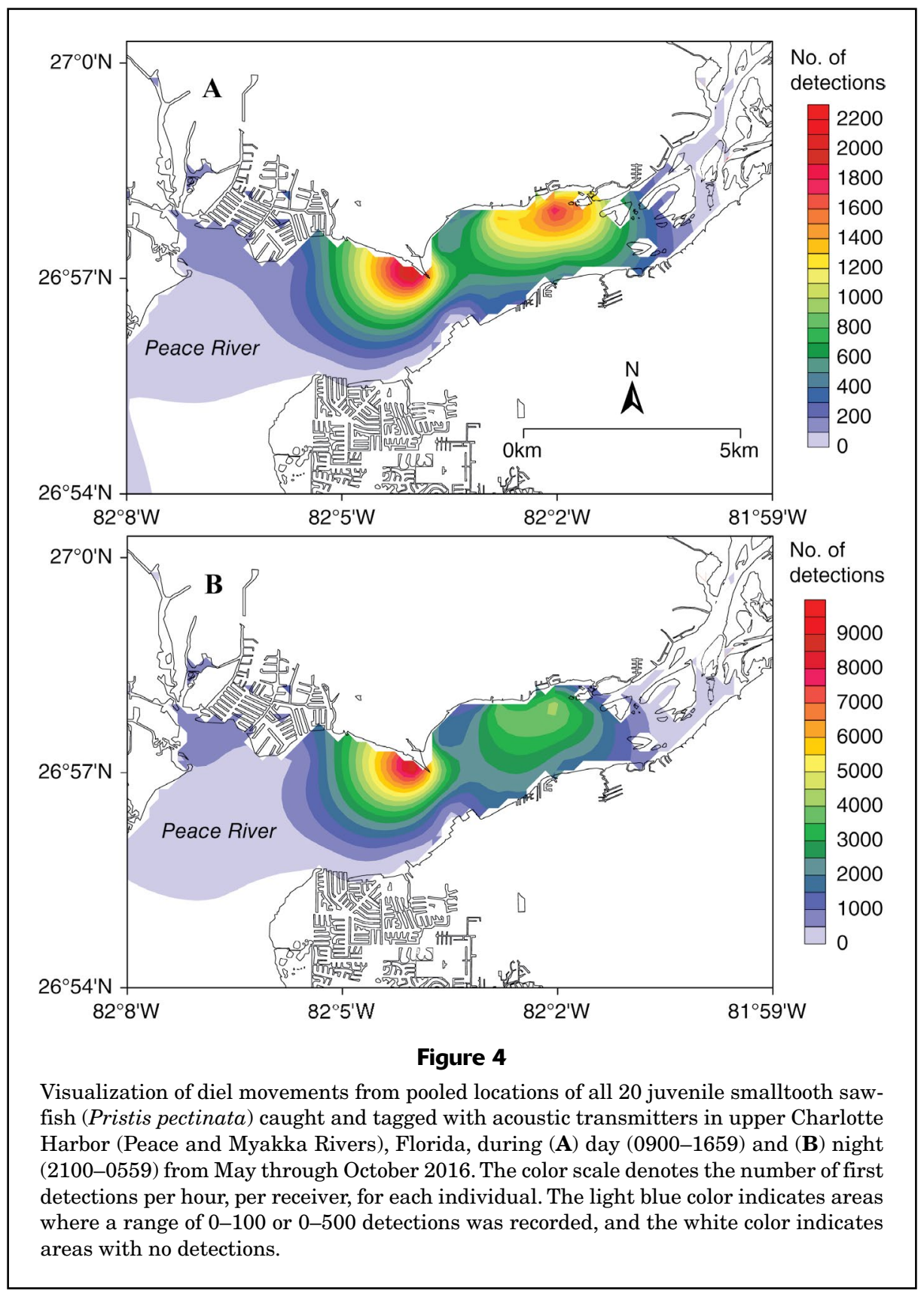

shoreline habitats, yet this study is the first to explore interactions with oyster reefs. Although juveniles did not select the restored oyster habitats more often than other available shallow habitats, as the reefs mature, perhaps juveniles will interact with them more often as habitat complexity increases and more potential forage species reside in the area (Harding and Mann, 2001).

Throughout the mixed semidiurnal tidal regime of the Charlotte Harbor estuarine system, smalltooth sawfish were detected on the southern shoreline significantly more often during the first flood and first ebb tides of the day, regardless of height. Because these first tides typically occurred at night, the primary driver for the across-river movement was likely diel, rather than tidal.

This study is the first to use an automated positioning system on a sawfish species, and results indicate that this technology is effective in the shallow habitats where individuals in the early life history stages of this and other relatively large fish species reside. The array of acoustic receivers allowed tracking data that traditionally have been collected manually to be automatically recorded $24 \mathrm{~h}$ a day. On the basis of the results of this preliminary, summerfocused study, similar arrays will be deployed in this and other nursery hotspots, including on the northern shoreline 


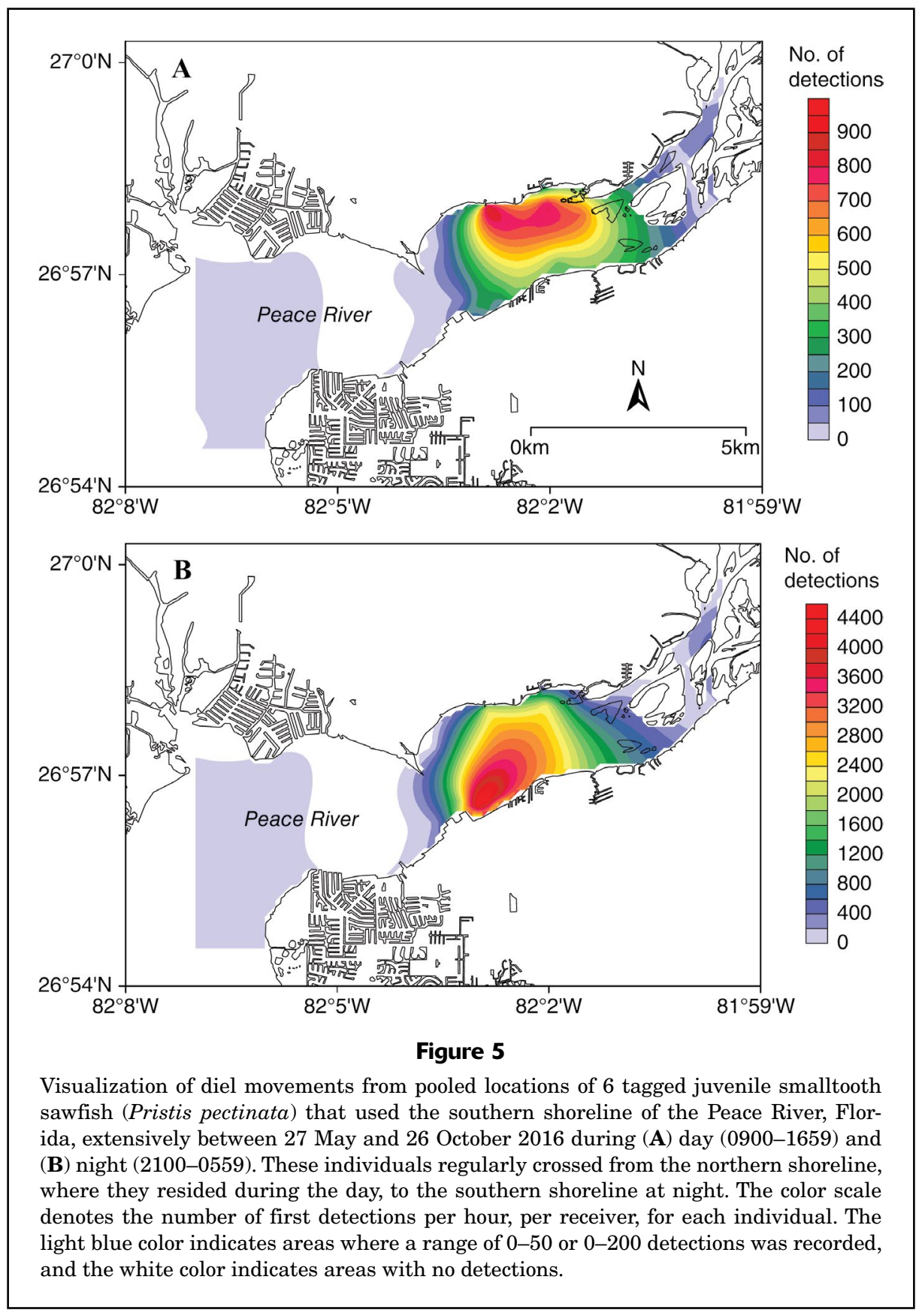




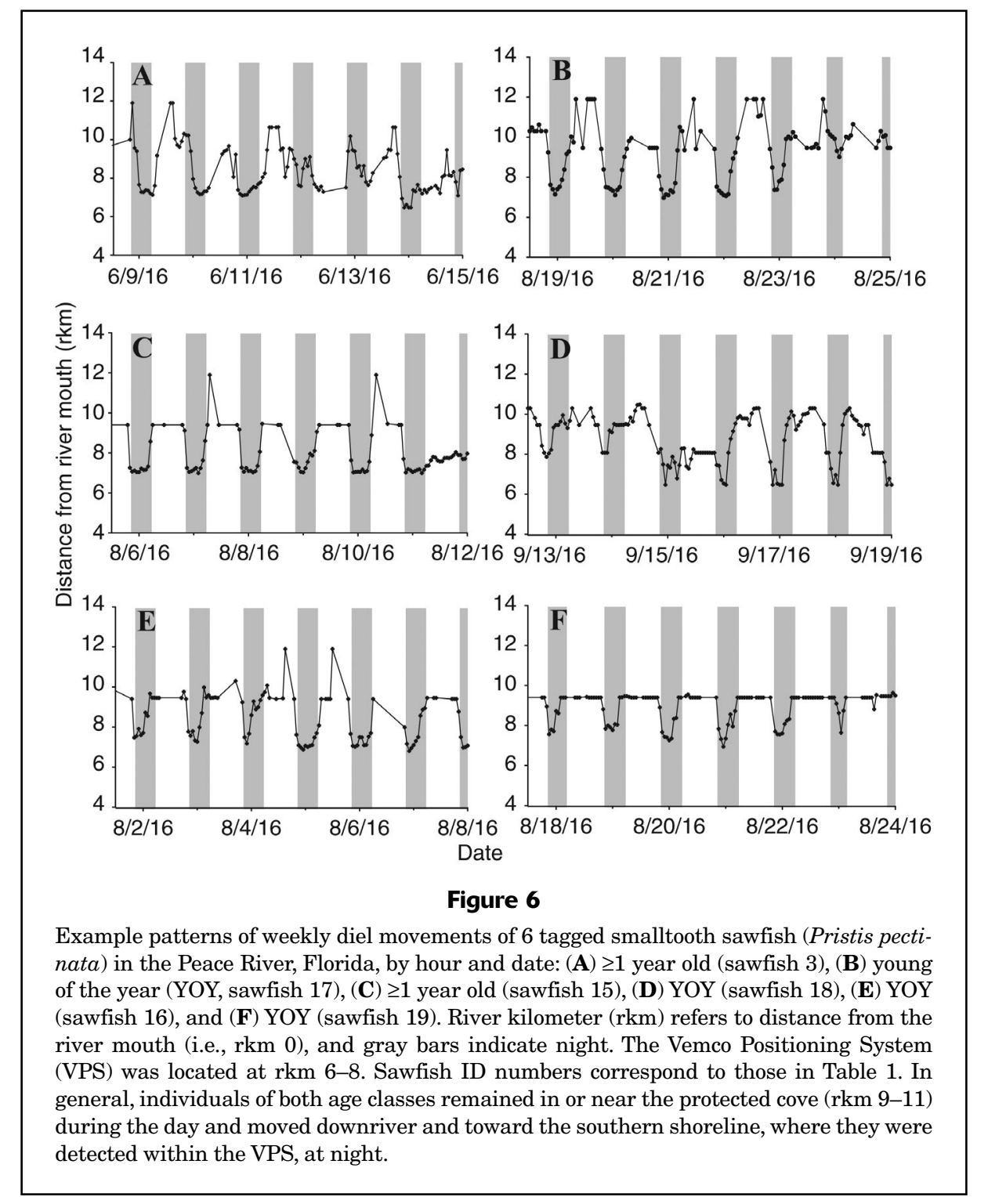

of the Peace River, to obtain fine-scale data on where juvenile smalltooth sawfish reside during the day. In addition, results of recent work indicate that internally placed acoustic tags can eliminate tag retention issues and allow collection of year-round data over multiple years (Poulakis and Grubbs, 2019); therefore, the tracking data from these arrays will provide a more complete picture of how juveniles use the most productive habitats within their broader nurseries. Although this technology offers many benefits, we recognize that it may not be accessible to all researchers because of the cost and maintenance involved, but it may be worth the investment if the most productive habitats can be identified for a species of interest.

\section{Acknowledgments}

This research was supported primarily by grant NA13NMF4720047 from the National Marine Fisheries Service (NMFS) under Section 6 of the U.S. Endangered Species Act (Cooperation with the States) and grant no. 02012016-001 from the Nature Conservancy. Research was conducted pursuant to NMFS endangered species permit no. 15802. C. Saari and 3 anonymous reviewers improved earlier versions of the manuscript. Statements, findings, conclusions, and recommendations are those of the authors and do not necessarily reflect the views or policies of the funding agencies. 

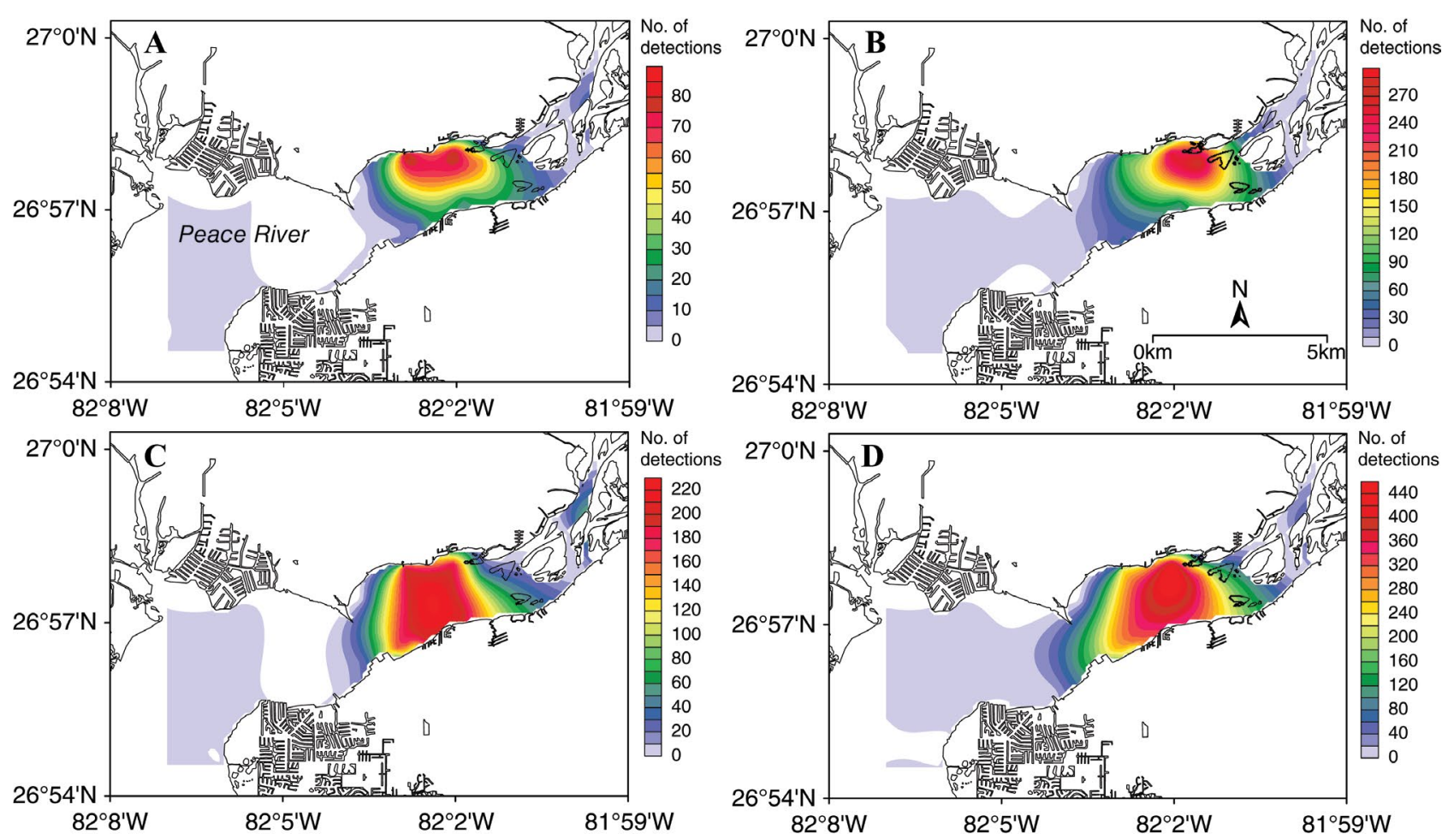

Figure 7

Visualization of diel movements of 2 tagged smalltooth sawfish (Pristis pectinata) in the Peace River, Florida, from May through October 2016: sawfish 16, a young of the year with a stretch total length [STL] of $1032 \mathrm{~mm}$, during (A) day and (C) night, and sawfish 3, a smalltooth sawfish with an age $\geq 1$ year and STL of $1435 \mathrm{~mm}$, during $(\mathbf{B})$ day and (D) night (sawfish ID numbers correspond to those in Table 1). These sawfish generally remained along the northern shoreline during the day, making nightly excursions across the river, sometimes to the southern shoreline. The color scale denotes the number of first detections per hour, per receiver, for each individual. The light blue color indicates areas where a range of $0-5,0-10$, or $0-20$ detections was recorded, and the white color indicates areas with no detections.

\section{Literature cited}

Allahdadi, M. N., F. Jose, E. J. D’Sa, and D. S. Ko.

2017. Effect of wind, river discharge, and outer-shelf phenomena on circulation dynamics of the Atchafalaya Bay and shelf. Ocean Eng. 129:567-580. Crossref

Beck, M. W., R. D. Brumbaugh, L. Airoldi, A. Carranza, L. D. Coen, C. Crawford, O. Defeo, G. J. Edgar, B. Hancock, M. C. Kay, et al.

2011. Oyster reefs at risk and recommendations for conservation, restoration, and management. BioScience 61:107-116. Crossref

Brame, A. B., T. R. Wiley, J. K. Carlson, S. V. Fordham, R. D. Grubbs,

J. Osborne, R. M. Scharer, D. M. Bethea, and G. R. Poulakis.

2019. Biology, ecology, and status of the smalltooth sawfish Pristis pectinata in the USA. Endanger. Species Res. 39:9-23. Crossref

Coen, L. D., R. D. Brumbaugh, D. Bushek, R. Grizzle, M. W. Luckenbach, M. H. Posey, S. P. Powers, and S. G. Tolley.

2007. Ecosystem services related to oyster restoration. Mar. Ecol. Prog. Ser. 341:303-307. Crossref

Collins, A. B., M. R. Heupel, and C. A. Simpfendorfer.

2008. Spatial distribution and long-term movement patterns of cownose rays Rhinoptera bonasus within an estuarine river. Estuar. Coasts 31:1174-1183. Crossref
Cressie, N., and T. R. C. Read.

1989. Pearson's $X^{2}$ and the loglikelihood ratio statistic $G^{2}$ : a comparative review. Int. Stat. Rev. 57:19-43. Crossref

Dye, B., F. Jose, and M. N. Allahdadi.

In press. Circulation dynamics and seasonal variability for the Charlotte Harbor estuary, southwest Florida coast. J. Coast. Res.

Federal Register.

2003. Endangered and threatened species; final endangered status for a distinct population segment of smalltooth sawfish (Pristis pectinata) in the United States. Fed. Regist. 68:15674-15680. [Available from website.]

Feldheim, K. A., A. T. Fields, D. D. Chapman, R. M. Scharer, and

G. R. Poulakis.

2017. Insights into reproduction and behavior of the smalltooth sawfish Pristis pectinata. Endanger. Species Res. 34:463-471. Crossref

Greenewalt, C. H.

1960. Hummingbirds, 250 p. Doubleday and Co. Inc., New York.

Hammett, K. M.

1990. Land use, water use, streamflow characteristics, and water-quality characteristics of the Charlotte Harbor inflow area, Florida. U.S. Geol. Surv. Water-Supply Pap. 2359-A, 64 p. [Available from website.] 
Harding, J. M., and R. Mann.

2001. Oyster reefs as fish habitat: opportunistic use of restored reefs by transient fishes. J. Shellfish Res. 20:951-959.

Heupel, M. R., J. K. Carlson, and C. A. Simpfendorfer.

2007. Shark nursery areas: concepts, definition, characterization and assumptions. Mar. Ecol. Prog. Ser. 337:287-297. Crossref

Heupel, M. R., S. Kanno, A. P. B. Martins, and C. A. Simpfendorfer.

2018. Advances in understanding the roles and benefits of nursery areas for elasmobranch populations. Mar. Freshw. Res. 70:897-907. Crossref

Huston, C. A., P. W. Stevens, R. M. Blaxton, S. G. Tolley,

R. M. Scharer, B. M. Tornwall, and G. R. Poulakis.

2017. Diel movements of juvenile smalltooth sawfish: implications for defining the size of a nursery hotspot. Endanger. Species Res. 34:311-322. Crossref

Huveneers, C., K. Apps, E. E. Becerril-García, B. Bruce,

P. A. Butcher, A. B. Carlisle, T. K. Chapple, H. M. Christiansen,

G. Cliff, T. H. Curtis, et al.

2018. Future research directions on the "elusive" white shark. Front. Mar. Sci. 5:455. Crossref

Lear, K. O., G. R. Poulakis, R. M. Scharer, A. C. Gleiss, and N. M. Whitney.

2019. Fine-scale behavior and habitat use of the endangered smalltooth sawfish (Pristis pectinata): insights from accelerometry. Fish. Bull. 117:348-359. Crossref

Mittermeier, R. A., W. R. Turner, F. W. Larsen, T. M. Brooks, and

C. Gascon.

2011. Global biodiversity conservation: the critical role of hotspots. In Biodiversity hotspots (F. E. Zachos and

Myers, $\mathrm{N}$ J. C. Habel, eds.), p. 3-22. Springer-Verlag, Berlin, Germany.

1988. Threatened biotas: "hot spots" in tropical forests. Environmentalist 8:187-208. Crossref

Nagelkerken, I., M. Sheaves, R. Baker, and R. M. Connolly.

2015. The seascape nursery: a novel spatial approach to identify and manage nurseries for coastal marine fauna. Fish Fish. 16:362-371. Crossref

Neu, C. W., C. R. Byers, and J. M. Peek.

1974. A technique for analysis of utilization-availability data. J. Wildl. Manage. 38:541-545. Crossref

Norton, S. L., T. R. Wiley, J. K. Carlson, A. L. Frick, G. R. Poulakis, and C. A. Simpfendorfer.

2012. Designating critical habitat for juvenile endangered smalltooth sawfish in the United States. Mar. Coast. Fish. 4:473-480. Crossref

O'Shea, O. R., M. J. Kingsford, and J. Seymour.

2010. Tide-related periodicity of manta rays and sharks to cleaning stations on a coral reef. Mar. Freshw. Res. 61:65-73. Crossref

Özgül, A., A. Lök, A. Ulaş, F. O. Düzbastılar, T. T. Tanrıkul, and

C. Pelister.

2015. Preliminary study on the use of the Vemco Positioning System to determine fish movements in artificial reef areas: a case study on Sciaena umbra Linnaeus, 1758. J. Appl. Ichthyol. 31(S3):41-47. Crossref

Polovina, J., I. Uchida, G. Balazs, E. A. Howell, D. Parker, and

P. Dutton.

2006. The Kuroshio Extension Bifurcation Region: a pelagic hotspot for juvenile loggerhead sea turtles. Deep Sea Res., II 53:326-339. Crossref

Poulakis, G. R., and R. D. Grubbs.

2019. Biology and ecology of sawfishes: global status of research and future outlook. Endanger. Species Res. 39:77-90. Crossref
Poulakis, G. R., P. W. Stevens, A. A. Timmers, T. R. Wiley, and C. A. Simpfendorfer.

2011. Abiotic affinities and spatiotemporal distribution of the endangered smalltooth sawfish, Pristis pectinata, in a south-western Florida nursery. Mar. Freshw. Res. 62:1165-1177. Crossref

Poulakis, G. R., P. W. Stevens, A. A. Timmers, C. J. Stafford, and C. A. Simpfendorfer.

2013. Movements of juvenile endangered smalltooth sawfish, Pristis pectinata, in an estuarine river system: use of nonmain-stem river habitats and lagged responses to freshwater inflow-related changes. Environ. Biol. Fish. 96:763-778. Crossref

Poulakis, G. R., P. W. Stevens, A. A. Timmers, C. J. Stafford, D. D. Chapman, K. A. Feldheim, M. R. Heupel, and C. Curtis.

2016. Long-term site fidelity of endangered smalltooth sawfish (Pristis pectinata) from different mothers. Fish. Bull. 114:461-475. Crossref

Rodriguez, A. B., F. J. Fodrie, J. T. Ridge, N. L. Lindquist, E. J. Theuerkauf, S. E. Coleman, J. H. Grabowski, M. C. Brodeur, R. K. Gittman, D. A. Keller, et al.

2014. Oyster reefs can outpace sea-level rise. Nat. Clim. Chang. 4:493-497. Crossref

Rogers, K. B., and G. C. White.

2007. Analysis of movement and habitat use from telemetry data. In Analysis and interpretation of freshwater fisheries data (C. S. Guy and M. L. Brown, eds.), p. 625-676. Am. Fish. Soc., Bethesda, MD.

Scharer, R. M., P. W. Stevens, C. P. Shea, and G. R. Poulakis.

2017. All nurseries are not created equal: large-scale habitat use patterns in two smalltooth sawfish nurseries. Endanger. Species Res. 34:473-492. Crossref

Scheel, D., and L. Bisson.

2012. Movement patterns of giant Pacific octopuses, Enteroctopus dofleini (Wülker, 1910). J. Exp. Mar. Biol. Ecol. 416-417:21-31. Crossref

Simpfendorfer, C. A., T. R. Wiley, and B. G. Yeiser.

2010. Improving conservation planning for an endangered sawfish using data from acoustic telemetry. Biol. Conserv. 143:1460-1469. Crossref

Semmens, B. X., E. R. Buhle, A. K. Salomon, and C. V. PattengillSemmens.

2004. A hotspot of non-native marine fishes: evidence for the aquarium trade as an invasion pathway. Mar. Ecol. Prog. Ser. 266:239-244. Crossref

Southall, E. J., D. W. Sims, J. D. Metcalfe, J. I. Doyle, S. Fanshawe, C. Lacey, J. Shrimpton, J.-L. Solandt, and C. D. Speedie.

2005. Spatial distribution patterns of basking sharks on the European shelf: preliminary comparison of satellite-tag geolocation, survey and public sightings data. J. Mar. Biol. Assoc. U.K. 85:1083-1088. Crossref

Waruhiu, C., S. Ommeh, V. Obanda, B. Agwanda, F. Gakuya, X.-Y. Ge, X.-L. Yang, L.-J. Wu, A. Zohaib, B. Hu, et al.

2017. Molecular detection of viruses in Kenyan bats and discovery of novel astroviruses, caliciviruses and rotaviruses. Virol. Sinica 32:101-114. Crossref

Whitty, J. M., D. L. Morgan, S. C. Peverell, D. C. Thorburn, and S. J. Beatty.

2009. Ontogenetic depth partitioning by juvenile freshwater sawfish (Pristis microdon: Pristidae) in a riverine environment. Mar. Freshw. Res. 60:306-316. Crossref

Zheng, L., and R. H. Weisberg.

2004. Tide, buoyancy, and wind-driven circulation of the Charlotte Harbor estuary: a model study. J. Geophys. Res. 109:C06011. Crossref 